Robert M.

La Follette School of Public Affairs

at the University of Wisconsin-Madison

Working Paper Series

La Follette School Working Paper No. 2005-002

http://www.lafollette.wisc.edu/publications/workingpapers

\title{
Enhancing Criminal Sentencing Options in Wisconsin: The State and County Correctional Partnership
}

\section{Pär Jason Engle}

Master of public affairs candidate, La Follette School of Public Affairs

at the University of Wisconsin-Madison

pjengle@wisc.edu

\section{David L. Weimer}

Professor, La Follette School of Public Affairs and Department

of Political Science at the University of Wisconsin-Madison

weimer@lafollette.wisc.edu

Another version of this paper appears in the Spring 2005 La Follette Policy Report, http://www.lafollette.wisc.edu/publications/policyreport

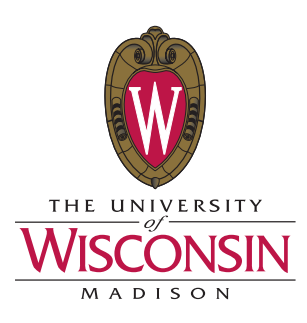

Robert M. La Follette School of Public Affairs 1225 Observatory Drive, Madison, Wisconsin 53706

Phone: 608.262.3581 / Fax: 608.265-3233

info@lafollette.wisc.edu / http://www.lafollette.wisc.edu

The La Follette School takes no stand on policy issues; opinions expressed within these papers reflect the views of individual researchers and authors. 


\title{
Enhancing Criminal Sentencing Options in Wisconsin: \\ The State and County Correctional Partnership
}

\author{
Par Jason Engle \\ (pjengle@wisc.edu) \\ David L. Weimer \\ (weimer@lafollette.wisc.edu)
}

January 27, 2005

* The preparation of this report was partly funded by the Robert M. La Follette School of Public Affairs. The authors thank Karen Faster and Andrew Reshovsky for helpful comments, but remain solely responsible for its content. 


\section{Executive Summary}

The number of people incarcerated in Wisconsin has risen dramatically during the last decade. The State of Wisconsin cannot accommodate all its prisoners in state facilities and therefore contracts with other entities for correctional services. Reducing reliance on contracting requires costly prison expansion or diversion of convicted felons to alternative correctional programs. An important source of alternatives is community corrections programs created and administered by counties. Under current arrangements, however, counties have neither a strong financial incentive nor adequate resources to provide many innovative correctional programs. The State and County Correctional Partnership (SCCP), which would provide counties with annual block grants and impose fees for state prison time served by Class $\mathrm{G}$ through I felons, seeks to create an environment in which counties can find innovative ways to divert felons safely and cost-effectively from incarceration in state prisons.

Under the SCCP, the State of Wisconsin would maintain full financial responsibility for the incarceration of those convicted of the most serious crimes, felony classes A through F. Counties would assume financial responsibility for the incarceration of those convicted of the less serious crimes, felony classes G through I. Specifically, after a five-year phase-in period, counties would receive an annual base-level block grant from the state equal to $\$ 18,800$ times the historical number of sentence-years given to Class G through Class I felons, based on the highest number of annual sentence-years in the period 2001 through 2003. Each county would be required to reimburse the state $\$ 18,800$ per sentence-year of Class $\mathrm{G}$ through Class I felons. The base-year grants would be adjusted annually in proportion to the change in the population aged 18 through 24 years in each county. Any residual funds (block grant minus payments to the state) would be allocated to county projects by a majority-rule governing body consisting of the District Attorney, or his or her designee; the County Executive, or his or her designee; and the senior Circuit Court Judge presiding in the county, or his or her designee. 
Executive Summary $\quad$ i

Table of Contents ii

$\begin{array}{ll}\text { Introduction } & 1\end{array}$

$\begin{array}{ll}\text { Background } & 1\end{array}$

Changes in Wisconsin Incarceration

State Correctional Capacity and Contracting

Increasing Correctional Costs

Cost-Effectiveness of Incarceration

The State County Correctional Partnership 3

Coverage: Classes A through F versus Classes G through I Initial Block Grants

Adjustment in Block Grants to Reflect Population Changes

Ramping Up to the Steady State

Calculating Annual Incarceration Fees

Local Governance

Cautions

Small County Variance

Relationship of Block Grants to Incarceration Fees

Class G to F Felony Creep

Net Widening

Conclusion

8

Appendix 1: Comparative Incarceration Rates

Appendix 2: Wisconsin Correctional Costs in Perspective

Appendix 3: Wisconsin Felony Classes and Class Distributions

Appendix 4: Mean Sentence

Appendix 5: Grants by County 


\section{Introduction}

Incarceration of felons in state prison provides benefits to society by reducing crime. However, it is also expensive. Alternatives to incarceration in state facilities might offer comparable benefits to society at lower cost. One possibility is the diversion of some prisoners who have committed less serious felonies to community corrections. Although unlikely to match the retributive and deterrent effects of incarceration, community corrections offers the potential for comparable levels of protection to the general public provided by correctional isolation and substantially greater opportunities for effective rehabilitation.

This report proposes a State and County Correctional Partnership (SCCP). It is based on the following assumptions: First, under the current policy, state correctional costs are likely to continue to grow. Second, community corrections programs may offer cost-effective alternatives to incarceration for some felons. Third, effective community corrections programs are most likely to arise from local initiatives. Fourth, local officials currently have neither a strong incentive nor adequate resources for developing, implementing, and administering community corrections programs. Fifth, allowing local officials to share in cost savings resulting from the diversion of felons from state incarceration would create an incentive to innovate. Sixth, officials in some counties would respond to the incentive by experimenting with innovative community corrections programs. Seventh, their experimentation would provide models for innovation in other counties.

The remainder of this report reviews the correctional circumstances in Wisconsin, sets out the details of the SCCP, and raises cautions about its use.

\section{Background}

Since 1990, Wisconsin has experienced dramatic increases in the number of felons serving sentences in state prisons. The increased prison population has increased state correctional costs and necessitated contracting for beds outside of state facilities. The increased incarceration rate has undoubtedly contributed to lower crime rates in Wisconsin. An important question for state policy-makers is whether further increases in the incarceration rate represent a cost-effective use of criminal justice resources.

\section{Changes in Wisconsin Incarceration}

The number of felons incarcerated in state correctional facilities in Wisconsin has increased from 7,465 in 1990 to 22,133 in 2002, contributing to an increase in the overall incarceration rate from 149 per 100,000 in 1990 to 393 per 100,000 in 2002. ${ }^{1}$ Wisconsin is not

\footnotetext{
${ }^{1}$ Bureau of Justice Statistics, "National Prisoner Statistics Data Series (NPS-1), Incarceration Rates for Prisoners under State or Federal Jurisdiction, per 100,000 Residents,” 2000; and Bureau of Justice Statistics, "Bureau of Justice Statistics Bulletin; Prison and Jail Inmates at Midyear 2003 - 05/04 NCJ 203947," Table 2: Prisoners under the Jurisdiction of State or Federal Correctional Authorities, 2003.
} 
alone in facing rising correctional populations and costs. In 2001, Wisconsin ranked $24^{\text {th }}$ in per capita incarceration among states and $10^{\text {th }}$ in expenditure per inmate. Among immediate neighbors, Wisconsin is second in its incarceration rate to Michigan, and second in per inmate cost to Minnesota. (See Appendix 1 for comparative incarceration rates.)

\section{State Correctional Capacity and Contracting}

Recent years have seen an expansion of the Wisconsin state prison system to accommodate the increased number of prisoners. Nonetheless, the increasing prison population during the last decade required the state to contract with out-of-state prisons and other providers for correctional services. At the end of 1996, the Wisconsin Department of Corrections began contracting for beds out of state to alleviate overcrowding in state institutions. In 1997 the average daily population housed in facilities under contract with Department of Corrections was 536. In 2003 the average daily population in contract beds was 3,739. As recently as September 2004, about 500 inmates were housed in facilities in other states with a similar number in contracted beds in local and federal facilities. ${ }^{2}$ Although the number of prisoners housed under contract has fallen substantially, and all inmates are currently housed in-state, further growth of the prison population under current policies during the next decade will probably result in continued reliance on contracting as a supplement to state facilities.

\section{Increasing Correctional Costs}

The increased prison population has resulted in increased costs. (See Appendix 2.) More than $\$ 800$ million per year is devoted to adult institutions in the 2004-2005 Wisconsin biennial budget, a steady rise of more than $\$ 500$ million since 1996. Correctional costs increased from 2.1 percent of the state budget in 1992 to 3.3 percent in 2002; state correctional costs also increased from 19.7 percent of total criminal justice system expenditures (state and local) in 1992 to approximately 29.9 percent in 2002. ${ }^{3}$ The average cost to the state of incarcerating an inmate for one year in a state facility in fiscal year 2002 was approximately $\$ 25,985 .{ }^{4}$ The cost of housing an inmate for one year in a contract facility is approximately $\$ 18,800$, which can be viewed as the current marginal cost to the State of Wisconsin of an additional year of felony sentence. ${ }^{5}$

\footnotetext{
${ }^{2}$ Wisconsin Department of Corrections, "Department of Corrections Offenders Under Control on September 24, 2004” and Legislative Fiscal Bureau, “Adult Correctional Facility Populations and Prison Contract Bed Funding,” Paper No. 235, May 15, 2003.

${ }^{3}$ U.S. Census Bureau, Governments Division; "State and Local Government Finances by Level of Government and State: 2001-02," "State and Local Government Finances by Level of Government and State: 1996- 97," "State and Local Government Finances by Level of Government and State: 1991-92.” http://www.census.gov/govs/www/estimate02.html.

${ }^{4}$ Secretary Matt Frank, “Cost of Incarceration in Wisconsin Prisons.” Presentation to Sentencing Commission, April 30, 2004.

${ }^{5}$ Based on \$51.46 per day. Legislative Fiscal Bureau, “Adult Correctional Facility Populations and Prison Contract Bed Funding,” Paper No. 235, May 15, 2003, p. 5.
} 


\section{Cost-Effectiveness of Incarceration}

Incarceration provides benefits to society. Beyond its retributive value, incarceration lowers crime rates by isolating those likely to commit crimes from the general population. Higher incarceration rates deter crimes by increasing the certainty of punishment; longer sentences deter crimes by increasing the severity of punishment. Incarceration may also reduce crimes in the future by providing a venue for rehabilitation.

The benefits of incarcerating any particular felon depends on the risks that the felon poses to society. As incarceration is costly, an important public policy question is whether there are cost-effective alternatives to incarceration for some offenders. Steve Aos and colleagues at the Washington State Institute for Public Policy have conducted comprehensive reviews of evaluations of correctional and other criminal justice programs. ${ }^{6}$ They identify a number of correctional alternatives to incarceration that appear to offer net reductions in public expenditures and positive net benefits to society when taking account of the costs of crimes. It is thus possible that community corrections programs could offer cost-effective alternatives to incarceration.

\section{The State County Correctional Partnership}

Probation is the most widely used alternative to incarceration in Wisconsin. Between the extremes of state prison terms and simple probation, there are a range of possible sanctions involving different levels of supervision, punishment, and treatment. Because these alternatives to prison keep offenders in their communities, they are often referred to as "community corrections." Currently, however, few options for community corrections are available in Wisconsin counties. Without intermediate sanctions providing more public protection than traditional probation, prosecutors and judges may see no responsible alternative to incarceration for many felons. It is possible that the availability of intermediate sanctions, such as house arrest, electronic surveillance, and supervised substance abuse treatment, would enable judges and prosecutors to divert more felons from state prison. It may also make available opportunities for more effective rehabilitation programs.

As the appropriateness of various forms of community corrections depends on the specific circumstances in different communities, the State of Wisconsin must rely on local communities to develop intermediate sanctions. Yet local communities have neither a strong incentive nor adequate resources to develop and implement them.

The proposed SCCP seeks to expand sentencing options for judges and prosecutors by creating a financial incentive for counties to create programs for diverting some felons from state prison sentences to community corrections. The program would allow counties to continue current practices without financial loss, but they would be able to increase their financial resources by finding less expensive alternatives to incarceration in state institutions.

\footnotetext{
${ }^{6}$ Steven Aos, Polly Phipps, Robert Barnoski, and Roxanne Lieb, “The Comparative Costs and Benefits of Programs to Reduce Crime,” Version 4.0, Washington State Institute for Public Policy, Olympia, Washington, May 2001.
} 
The SCCP has six major components. First, it would apply only to Class G through Class I felonies, less serious crimes such as receiving stolen property or possession of controlled substances. The state would continue to have full fiscal responsibility for the sentences given to those convicted of the most serious felonies, Class A through Class F. Second, counties would be given base-year annual grants equal to the annual cost of contract incarceration times the number of years their Class G through Class I felons were sentenced in a base period. Third, the base-year grants would be adjusted annually to reflect the percentage change in the number of 18- to 24-year olds in the county population. The grants would be diverted from the budget of the Department of Corrections. Fourth, there would be a five-year phase-in period to reduce the likelihood that diversions from the Department of Corrections budget would exceed savings from reductions in contracting costs. Fifth, each county would pay to the Department of Corrections the annual cost of contracted incarceration for each sentence-year of its newly convicted Class $\mathrm{G}$ through Class I felons. Sixth, any residual between the annual grant and the payments to the state would be available for use by the county.

Note that the Department of Corrections would lose an amount equal to the annual cost of contracted incarceration for each felon diverted by the counties below the historical base. Nonetheless, until contracted incarceration has been eliminated, the Department of Corrections could offset this revenue loss by eliminating a corresponding contracted incarceration.

The following sections explain the six elements of the SCCP in more detail.

\section{Coverage: Classes A through $F$ versus Classes $G$ through I}

Wisconsin 2001 Act 109 introduced a new system of felony classification that placed all felonies into nine felony classes, ranging from Class A with a maximum term of confinement of life in prison, to Class I with a maximum term of confinement of 1.5 years. Class $G$ and below include offenses involving the least culpable mental states and lesser harms to victims. ${ }^{7}$ For example, Class F includes burglary, second degree reckless injury, first degree recklessly endangering safety, and injury by intoxicated use of vehicle with a maximum term of confinement of 7.5 years, while Class G includes third degree sexual assault, second degree recklessly endangering safety, felony possession of a firearm, theft, and receiving stolen property with a maximum term of confinement of 5 years. Analysis shows that classes $\mathrm{G}, \mathrm{H}$, and I also appear in practice to involve relatively short sentences as compared to Class F and above. Consequently, the SCCP applies only to Class G through Class I felonies.

\section{Basic Block Grants}

The basic annual block grant would allow counties to continue current practices without financial penalty. It would equal the number of years of sentence given in the county to Class $\mathrm{G}$ through Class I felons in some base period (BYS) times the cost of contracting for a year of custody (MCOS) outside of state facilities. The MCOS value is $\$ 18,800$.

\footnotetext{
${ }^{7}$ Thomas J. Hammer and Michael B. Brennan, “Truth in Sentencing Part II: 2001 Act 109 Crimes and Their Penalties," paper presented at Truth in Sentencing II - A Program for the Criminal Defense Lawyer sponsored by the Wisconsin State Public Defender, January 2003, p. 10.
} 


\section{Adjustment in Block Grants to Reflect Population Changes}

Demographic changes are likely to cause changes in crime rates, and, therefore, numbers of felony convictions. A relevant and available demographic variable is the number of people in the county between the ages of 18 and 24 years, the most criminally prone adult age group. The initial block grant would be adjusted each year to reflect the percentage change in the number of people in the county in this age group.

\section{Ramping Up to the Steady State}

The annual grants take account of the total number of sentence-years that will result from convictions occurring each year. To reduce the likelihood that diversions from the Department of Corrections budget would exceed savings from reductions in contracting costs, the basic annual grants would be phased in over a five-year period. Specifically, the first-year grant for the SCCP would equal 1/5 of the basic annual grant, the second-year grant would equal 2/5 of the basic grant, and so forth. The fifth-year grant would bring the SCCP to a steady state with counties receiving their full basic annual grant.

\section{Calculating Annual Incarceration Fees}

In the steady state beginning in year five of the SCCP, the annual fees that counties would pay to the Department of Corrections would equal the MCOS used in the determination of the initial annual grant, $\$ 18,800$, times the number of years to which those convicted of Class G to Class I felonies were sentenced. The number of sentenceyears would be determined by summing the actual sentence lengths of those convicted.

During the five-year ramp-up to the steady state, the fees charged to counties would follow the same pattern as the grants with the first-year fee equal to $1 / 5$ of the total sentenced years times the MCOS, the second-year fee equal to 2/5 of the total sentenced years times the MCOS, and so forth.

\section{Local Governance}

Each county would have a three-member SCCP board consisting of the District Attorney, or his or her designee; the County Executive, or his or her designee; and the senior Circuit Court Judge presiding in the county, or his or her designee. The board would allocate any residual funds (block grant minus payments to the state) to county purposes by majority rule vote. Residual funds could support community sentencing or other criminal justice programs, or they could be transferred to county general revenues. The board likely would be the focal point for innovation, possibly organizing efforts to secure external grants for innovative programs and overseeing the assessment of implemented programs. Counties that wished to operate as a single unit by pooling their grants and fees would be allowed to constitute unified SCCP boards. 


\section{Cautions}

Several problems could arise during implementation of the SCCP related to risks for small counties, the temptation of Department of Corrections to change the terms of the grant and fee structure, the financial incentive for local officials to shift felons from Class $G$ to Class F, and the expansion of community sentencing to include some defendants who now have charges dropped or receive probation.

\section{Small County Variance}

Counties with relatively small numbers of felony convictions per year are likely to experience greater variance in the fees they pay to the state and therefore are more likely to experience years in which fees exceed their block grants. The impact of this risk could be mitigated by allowing counties with smaller volumes of felony convictions to borrow against the next year's grant. Alternatively, during the first few years of implementation a risk pool could be formed by assessing a small percentage charge on block grants. Counties with unusually high fees could seek compensation from the risk pool.

\section{Relationship of Block Grants to Incarceration Fees}

Correctional partnerships between the state and counties are not entirely new to Wisconsin. Since 1981, Wisconsin juvenile justice institutions have operated under a costsharing program. In 1979, in reaction to high rates of youth institutionalization, Wisconsin introduced Youth Aids to make counties financially accountable for the costs of sending youths to state facilities. Its mechanism is similar to the SCCP: grants are awarded by formula to each county and the state charges the county per diem fees for institutionalized youths. The per diem fees, however, are based on average rather than marginal costs and not directly related to the grants. As a consequence, some counties experienced rising juvenile institutionalization fees even though their use of institutionalization remained unchanged.

Under the SCCP, Department of Corrections would have an incentive to increase fees without making corresponding increases in the base grants. Therefore, creation of the SCCP must clearly tie the size of block grants to the fee. Any change in the fee, say to reflect changes in contracting costs, should be accompanied by a recalculation of the base grant using the new fee amount.

\section{Class G to F Felony Creep}

The SCCP would create a financial incentive for judges and prosecutors to move some sentences that would otherwise be at the Class $\mathrm{G}$ level to Class F, thereby avoiding fees altogether. To guard against this possibility, it would be important to make annual comparisons of the percentage changes in these felony classes from the base-year figures. Publication of these figures might be sufficient to prevent such shifts. However, if apparent shifts persisted, then a fee might be added for percentage increases beyond some level. 


\section{Net Widening}

Just as the greater availability of intermediate sentences would divert some inmates from state prison to community corrections, it might also result in some defendants being drawn into community corrections who currently would either not be prosecuted and convicted or, if convicted, given standard probation. Such net widening is not necessarily undesirable if community corrections provides a more appropriate punishment for those drawn into the net. However, it would result in greater costs for community corrections programs than would be predicted solely on the basis of diversions from state prisons.

\section{Conclusion}

The SCCP would not guarantee the expansion of cost-effective community corrections in Wisconsin. Nonetheless, it would facilitate local efforts to discover, implement, and assess such alternatives.

As the state would retain responsibility for the incarceration of those convicted of the most serious felonies, the SCCP would not present local criminal justice systems with a financial incentive to avoid state prison terms for felons posing the greatest threat to the community. The SCCP would create an opportunity for locally-elected officials to initiate community correctional alternatives that they believe are most appropriate for their local circumstances. Some counties might very well continue current practices and thereby see no significant net fiscal effects. Other counties, however, may develop diversion programs with the knowledge that local revenues would be enhanced by $\$ 18,800$ per sentence-year diverted. As the $\$ 18,800$ equals the current contracting cost for the state for each sentence year, the SCCP would be approximately fiscally neutral for the state until contracting is eliminated. Counties could use residual funds for any purposes, including programs to improve the courts, prosecution, police, or local corrections. Over time, cases of successful innovation would serve as models for possible replication in other counties. 